\title{
Construcción de un vector para la integración cromosomal de un gen de fitasa de Bacillus licheniformis
}

\section{Construction of a vector for stable chromosomal integration of a Bacillus licheniformis phytase gene}

\author{
Maria Teresa Fernández ${ }^{1 *}$, Hilda Rodríguez ${ }^{1}$, Tania Gonzalez ${ }^{1}$, Isabel Goire ${ }^{1}$
}

1 Instituto Cubano de Investigación de los Derivados de la Caña de Azúcar (ICIDCA), Via Blanca de Azúcar (ICIDCA), Via Blanca 804, AP 4026, CP 11000. Ciudad de la Habana. Cuba. Teléfono: (537)6967015; Fax: (537)988243 Email Maria Teresa Fernández: maritere.fernandez@icidca.edu.cu

Presentado: $17 / 02 / 2008$ Aceptado: 31/03/2009 Publicado online: 28/08/2009

\section{Resumen}

Las fitasas son una clase especial de fosfatasas que catalizan la hidrólisis secuencial del fitato. La incapacidad de las plantas para utilizar el fósforo a partir de los fitatos del suelo es debido a la baja actividad de fitasas en sus raíces. Los microorganismos del suelo juegan un importante papel en los procesos que afectan la transformación de los compuestos fosforados. Muchos de ellos pueden solubilizar el fósforo a partir de los fitatos, mediante la liberación de fitasas. Este proceso permite la movilización del fósforo hacia las plantas y un mejor aprovechamiento de este nutriente. Sin embargo, muchas bacterias carecen de los genes que codifican para estas enzimas, lo que disminuye la disponibilidad de este elemento en el suelo. Una alternativa es mejorar las rizobacterias en cuanto a su capacidad de solubilizar los fitatos del suelo, mediante la transformación genética. En este trabajo el gen phyL de Bacillus licheniformis fue clonado en el vector de liberación suicida pJMT6 (vector derivado del sistema pUT/mini Tn5). La construcción recombinante que contiene un marcador

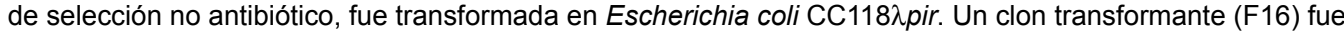
seleccionado y posteriormente caracterizado. Estos resultados constituyen un primer paso para desarrollar rizobacterias promotoras del crecimiento mejoradas en cuanto a la producción de actividad fitasa recombinante, como alternativa para reducir la contaminación ambiental y mejorar la productividad de los cultivos.

Palabras claves: Bacillus licheniformis, fitasas, enzimas recombinantes en E. coli, solubilización de fósforo, rizobacterias

\begin{abstract}
Phytases are a special class of phosphatases that catalyze the sequential hydrolysis of phytate. The inability of plants to utilize phosphorous from soil phytates is due to the low phytase activity in plant roots. Soil microorganisms play an important role in the processes that affect the transformation of phosphate containing compounds. Many of them can solubilize phosphorus from phytates, by means of the liberation of phytases. This process allows the mobilization of phosphorus towards the plants and a better utilization of this nutrient. Nevertheless, many soil bacteria lack gene coding for these enzymes, which diminishes the availability of this element in soil. One alternative to obtain improved rhizobacteria in relation to their capacity to solubilize soil phytates is by their genetic transformation with genes that codify for those enzymes. In this work, the gene phyL from $B$. licheniformis was cloned into the suicide delivery vector pJMT6 (a derivative vector from the pUT/mini Tn5 system). The recombinant construction, which contains a non-antibiotic resistance selection marker, was transformed in Escherichia coliCC118 $\lambda$ pir. A transformant clone (F16) was selected and further characterized. These results are a first step to develop improved growth promoting rhizobacteria as for the production of recombinant phytase activity, as alternative to reduce environmental pollution and to improve crops productivity.
\end{abstract}

Keywords: Bacillus licheniformis, phytases, recombinant enzymes in E. coli, phosphate-solubilitation, rhizobacteria.

\section{Introducción}

El fósforo $(\mathrm{P})$ es un macronutriente mineral esencial para las plantas. Aunque puede encontrarse en los suelos en diferentes formas minerales y como materia orgánica, su baja solubilidad disminuye su disponibilidad para las plantas. Las reservas mundiales de $\mathrm{P}$ son limitadas y tendrán una reducción considerable en los próximos ańos (Steen, 1998). El descubrimiento de la capacidad de algunos microorganismos para solubilizar fuentes de P orgánico/inorgánico del suelo y hacerlo disponible para las plantas ha sido el centro de atención de varias investigaciones durante muchos ańos (Rodríguez y Fraga 1999). La solubilización de $\mathrm{P}$ por estos microorganismos puede ser a través de la producción de enzimas extracelulares o la exudación de ácidos orgánicos con posible estimulación para el crecimiento de las plantas (Rodríguez et al. 2006). Es por eso que el uso de estas bacterias para incrementar el rendimiento de cultivos de interés agrícola presenta grandes perspectivas y son comercializadas en numerosos países (Zahir et al. 2004). La sustitución parcial o total de los fertilizantes químicos por productos biológicos es un aporte fundamental, no sólo a la disminución de los costos en la agricultura, sino al desarrollo de una agricultura orgánica y sostenible (Li et al. 2007).
Una gran proporción de los compuestos orgánicos del suelo permanece pobremente caracterizada. Sin embargo, se ha determinado que el ácido fítico o myo-inosotol 1,2,3,4,5,6 ácido hexakisfosfórico y sus derivados ión-metálicos (fitatos) representan los componentes principales, alcanzando en ocasiones hasta más del $50 \%$ del P orgánico total (Richardson 2001). Sus grupos fosfato pueden ser removidos hidrolíticamente en myoinositol, myo-inositol fosfatos y fosfatos inorgánicos (Konietzny \& Greiner 2003), por enzimas denominadas fitasas (myo-inositolhexaquisfostato 3-fosfohidrolasa), ampliamente distribuidas en plantas, microorganismos y en algunos tejidos animales (Vohra y Satyanarayana 2003).

Investigaciones recientes han mostrado que las fitasas de origen microbiano son las más prometedoras para las aplicaciones biotecnológicas (Jorquera et al., 2008). Muy pocas fitasas han sido descritas como altamente específicas para el ácido fítico, entre ellas se encuentran las fitasas alcalinas del género Bacillus. La clonación de genes que codifican fitasas alcalinas de diferentes especies de Bacillus han sido reportadas por diferentes autores (Kim et al. 1998, Kerovuo et al. 1998). El gen phyL de Bacillus licheniformis, que codifica una fitasa alcalina, ha sido considerado una herramienta potencial para las aplicaciones ambientales, 
Tabla 1. Plásmidos y cepas usadas en este estudio.

Plásmidos

\begin{tabular}{|c|c|c|}
\hline pBSOK-APL & $\begin{array}{l}\text { Apr, } 4.086 \mathrm{~kb} \text {; deriva del pBSK, porta el gen phyL de Bacillus licheniformis } \\
(1.000 \mathrm{~kb}) \text { precedido de un péptido señal de Azospirillum irakense (APL). }\end{array}$ & Lim, W. (Com. pers.) \\
\hline pBSKNpt & $\begin{array}{l}\text { Apr, 3.174, deriva del pBSK, porta el promotor nptII ( } \sim 178 \text { bp }) \text { del } \\
\text { pUTminiTn5ngfp por una digestión ClaI/NdeI }\end{array}$ & Lim, W. (Com. pers.) \\
\hline pBSNpt-APL & $\begin{array}{l}\text { Apr, similar al pBSKNpt, porta el fragmento APL en el sitio BamH/NdeI } \\
(4.246 \mathrm{~kb}) \text {. }\end{array}$ & Este estudio \\
\hline pJMT6 & Apr, pUT/mini-Tn5, Tel Kr (8.2 kb). & Sánchez-Romero et al. 1998 \\
\hline pF16 & $\begin{array}{l}\text { Apr, obtenido a partir del pJMT6 con el gen phyL insertado en el sitio Not I } \\
(9.450 \mathrm{~kb}) \text {. }\end{array}$ & Este estudio \\
\hline \multicolumn{3}{|l|}{ Cepas } \\
\hline Escherichia coli DH5aa & $\mathrm{F}^{\prime} \varphi 80 \mathrm{~d}$ lacZ $\left.\Delta \mathrm{M} 15\right]$ end $\mathrm{A}, \mathrm{hsdR}$, supE, thi, recA, gyrA, relA, $\lambda$ - & Sambrook et al. 1989 \\
\hline Escherichia coli CC118גpir & $\begin{array}{l}\Delta(\text { ara-leu) araD } \triangle l a c X 74 \text { phoA thi-1 rpsE rpoB lisogenizada con el fago } \lambda \text { pir } \\
\text { (Rfr) (Spr). }\end{array}$ & Herrero et al. 1990 \\
\hline Escherichia coli CC118גpir F16 & Similar a E. coli CC118ג pir, pero con el pF16. & Este estudio \\
\hline
\end{tabular}

por su actividad a $\mathrm{pH}$ neutro, elevada termoestabilidad y gran afinidad por el ácido fítico (Tye et al. 2002).

La ingeniería genética permite la introducción de nuevos caracteres y/o la sobre-expresión de caracteres en microorganismos. Es por esto que la expresión heteróloga del gen $p h y L$ puede ser una vía para el mejoramiento de cepas en cuanto a la solubilización de los fitatos del suelo, con vistas al desarrollo de nuevos biofertilizantes. Hasta la fecha no se ha descrito ningún trabajo relacionado con la integración cromosomal de genes relacionados con el gen $p h y L$.

El presente trabajo describe la construcción de un vector derivado del sistema $\mathrm{pUT} / \mathrm{mini} \mathrm{Tn} 5$, mediante la clonación del gen phyL de Bacillus licheniformis y su transformación en E.coli CC1 18 $\lambda$ pir, como un paso esencial para su futura transferencia en rizobacterias de interés agrícola.

\section{Materiales y métodos}

Plásmidos, cepas bacterianas, medios y condiciones de cultivo

Los plásmidos y cepas bacterianas se muestran en la Tabla 1. Las cepas de Escherichia coli DH5- $\alpha$ y CC118 $\lambda$ pir fueron crecidas en medio LB líquido (en $\mathrm{gL}^{-1}$ : triptona, 10; extracto de Levadura, 5; NaCl, 10; pH 7) y en Agar LB (LB suplementado con $2 \%$ de agar (oxoid)). En los medios selectivos, la ampicilina (Ap) fue usada a $100 \mu \mathrm{g} / \mathrm{mL}$ y el telurito de potasio $\left(\mathrm{K}_{2} \mathrm{TeO}_{3}\right)$ a $80 \mu \mathrm{g} / \mathrm{mL}$.

El crecimiento de las dos cepas en los medios líquidos fue realizado a $37{ }^{\circ} \mathrm{C}$ en un agitador orbital a $175 \mathrm{rpm}$ (LABLINE). Los cultivos en medios sólidos se incubaron a esta

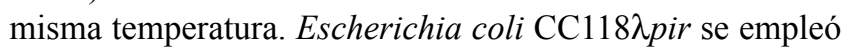
como hospedero para propagar los plásmidos que contienen un origen de replicación R6K (de Lorenzo y Timmis, 1994).

Las construcciones pBSOK-APL y pBSNpt fueron gentilmente donadas por Wallace B. L. Lim, profesor asociado, Departamento de Zoología de la Universidad de Hong Kong.

\section{Técnicas del ADN recombinante}

Las manipulaciones del ADN (cortes con endonucleasas de restricción, reacciones de desfosforilación y de ligazón, purificación de plásmidos), se realizaron básicamente según los métodos descritos por Sambrook y Russell (2001), utilizando enzimas de la casa comercial New England Biolabs. La preparación y transformación de las células competentes de $E$. coli se realizó según el método del $\mathrm{CaCl}_{2}$ descrito por Hanahan (1983).

\section{Clonaje del gen $p h y L$ en el vector integrativo pJMT6}

La clonación del gen phyL de Bacillus licheniformis en el plásmido de liberación suicida para la integración cromosomal se llevó a cabo en dos etapas (Fig. 1). En la primera etapa, el

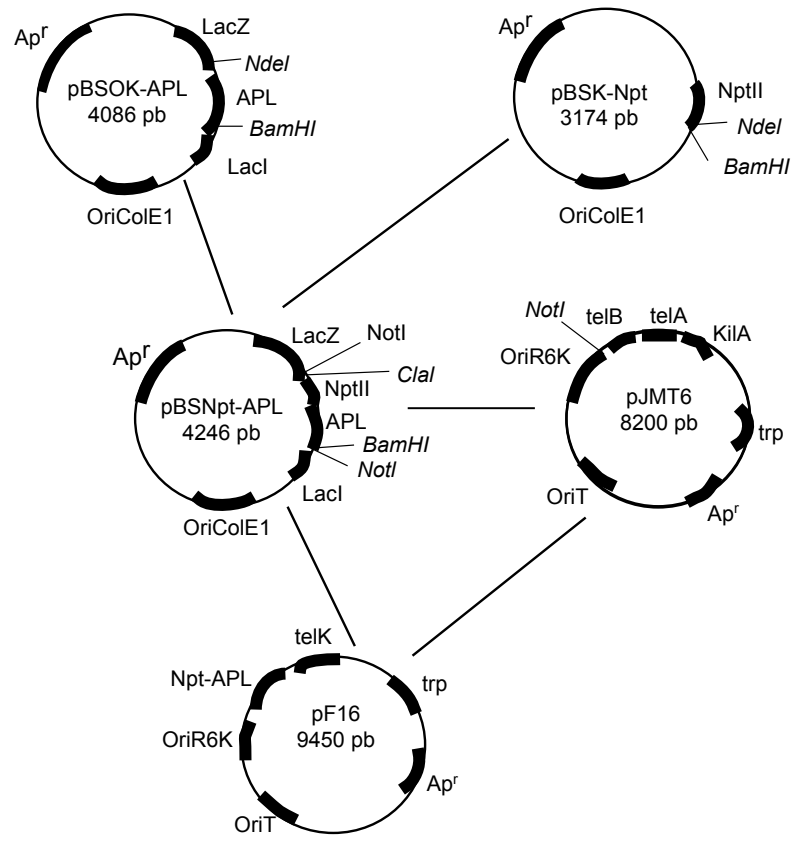

Figura 1. Estrategia empleada en el clonaje del gen phyL en el vector integrativo pJMT6, telK (genes de resistencia a telurito, telB, telA, kilA), trp (gen que codifica para la enzima transposasa), Npt-APL (secuencia nptIl-(peptido señal)-phyL), OriR6K: (origen de replicación dependiente de la proteína $\pi$. codificada por el gen pir) 
gen $p h y L(\mathrm{PL})$, precedido del péptido señal de la peptato liasa (A) secretada por Azospirillum irakense, fue subclonado en el vector pBSKNpt para de esta forma colocar el gen bajo el control del promotor $n p t I I(\mathrm{Npt})$ (Dandie et al. 2001) y flanquear el fragmento a transferir con sitios de restricción Not $I$ en los extremos 5' y 3'. Para ello se realizó la digestión con las enzimas de restricción BamHI y NdeI, que liberan el fragmento APL y linealizan el vector pBSKNpt. Se realizó la transformación del plásmido recombinante en $E$. coli $\mathrm{DH} 5 \alpha$ y los clones positivos se seleccionaron en medio LB sólido con ampicilina.

La segunda etapa consistió en la clonación del fragmento Npt-APL liberado mediante restricción con Not $I$ en el vector integrativo pJMT6 digerido con la misma enzima. El plásmido recombinante se transformó en $E$. coli CC1 $18 \lambda$ pir y los clones positivos se seleccionaron en medio LB sólido suplementado con ampicilina y telurito de potasio. El vector pJMT6 tiene el origen de replicación R6K, por lo tanto requiere de una proteína específica para su replicación, la proteína codificada por el gen pir, por lo que solamente puede ser mantenido en cepas hospederas que produzcan esta proteína. Presenta además el origen de transferencia ori $T$, lo que es establemente mantenido en lisógenos $\lambda$ pir o en cepas de E. coli con el gen pir recombinado en su cromosoma (Hansen et al. 1997).

En ambas etapas, los transformantes de E. coli portadores de los plásmidos que contienen el gen $p h y L$ fueron comprobados por análisis de restricción.

\section{Determinación de actividad fitasa}

La actividad fitasa fue evaluada y cuantificada según lo descrito por Shimizu (1992), usando como sustrato fitato de sodio en los extractos celulares y en el sobrenadante de los cultivos líquidos, de la manera siguiente:

Las células fueron cultivadas en matraces de $500 \mathrm{~mL}$ con 100 $\mathrm{mL}$ de medio $\mathrm{LB}$ con ampicilina durante $24 \mathrm{~h}$ respectivamente. Se tomaron muestras del cultivo a las $0,8,16,24 \mathrm{~h}$. Seguidamente las células fueron colectadas por centrifugación a 10000 $\mathrm{x} g$ durante $10 \mathrm{~min}$, y resuspendidas en buffer Tris-Cl-Ca 100 $\mathrm{mM}, \mathrm{pH} 7$ hasta una DO $(600 \mathrm{~nm})$ final de 0,8 de la dilución 1:100 de cada suspensión celular. Posteriormente, fueron tratadas con ultrasonido durante 4 ciclos de 1 min y centrifugadas a 10000 x g durante $30 \mathrm{~min}$. La reacción enzimática se inició, adicionando $1 \mathrm{~mL}$ de solución de fitato de sodio $1,5 \mathrm{mM}$ a 1 $\mathrm{mL}$ del extracto crudo. Después de $30 \mathrm{~min}$ de incubación a 50 ${ }^{\circ} \mathrm{C}$, la reacción fue detenida con un $1 \mathrm{~mL}$ de ácido tricloracético 10\%. La presencia de Pi (Fósforo inorgánico) se detectó por el incremento en la absorbancia a una longitud de onda de 660 $n m$ en un espectrofotómetro. La actividad en el sobrenadante se determinó de la misma manera que en el extracto. Una unidad de enzima fue definida como la cantidad de enzima que hidroliza $1 \mu \mathrm{mol}$ de P $i$ por minuto bajo las condiciones ensayadas.

\section{Determinación del crecimiento celular}

La cepa de $E$. coli CC118 $\lambda$ pir transformada con el plásmido pF16, y en el control (E. coli transformada con el pJMT6 sin el gen $p h y L)$ se cultivaron en matraces de $500 \mathrm{~mL}$ con $100 \mathrm{~mL}$ LB ampicilina durante $24 \mathrm{~h}$ a $37^{\circ} \mathrm{C}$. Cada dos horas se tomaron las muestras de los cultivos para cuantificar el crecimiento celular y elaborar las correspondientes curvas de crecimiento. El crecimiento celular en los cultivos líquidos fue determinado por medio del cambio en el valor de la absorbancia a una longitud de onda de $600 \mathrm{~nm}$ en un espectrofotómetro, con cubetas de $1 \mathrm{~cm}$ del paso de luz.

\section{Análisis estadísticos}

Todas las determinaciones de actividad enzimática y crecimiento celular fueron realizadas por triplicado. Se realizó el análisis de varianza de las medias correspondientes a los valores de actividad y las velocidades específicas de crecimiento, calculadas en la fase exponencial del cultivo, de las diferentes cepas estudiadas. Estos análisis se realizaron con el paquete estadístico Statistica v 6.0 .

\section{Resultados y discusión}

\section{Selección y caracterización de clones de $E$. coli CC118 $\lambda$ pir transformados con el gen $p h y L$}

El vector de liberación suicida pJMT6 porta los genes kilA, telAB, que codifican para resistencia a las sales de telurito (típicamente telurito de potasio, $\mathrm{K}_{2} \mathrm{TeO}_{3}$ ), un marcador para la construcción de cepas destinadas a ser liberadas al medioambiente. El pJMT6 fue empleado inicialmente por de Lorenzo et al. (1998) para modificar genéticamente la cepa Pseudomona putida KT2442 a través de la integración al azar del minitransposón mini-Tn 5 a su cromosoma. La cepa E coli CC1 $18 \lambda$ pir por si sola no puede crecer en un medio con $\mathrm{K}_{2} \mathrm{TeO}_{3}$, al carecer de los genes kilA, telAB (Sánchez-Romero et al. 1998). Cuando se transforma con el pJMT6 o un vector derivado de este como el pF16, no sólo se produce el crecimiento, sino que las colonias muestran un fenotipo característico: adquieren un color negro producto de la reducción del telurito por las células y la formación de telurio metálico insoluble, que es de coloración negro, lo que hace a las colonias fácilmente distinguibles (Fig. 2).

La transformación del plásmido recombinante en $E$. coli CC118 $\lambda$ pir se logró con una frecuencia de $1,4 \times 10^{5}$ unidades formadoras de colonias (CFU)/ $\mu \mathrm{gADN}$. Esta frecuencia es comparable a la obtenida en la transformación de otros plásmidos recombinantes en esta misma cepa (datos no publicados).

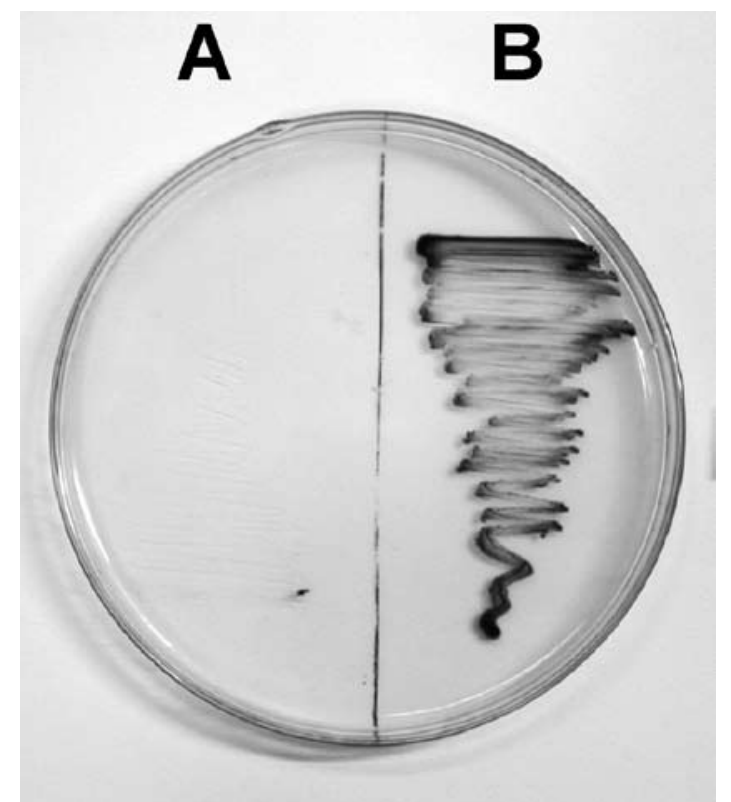

Figura 2: Resistencia al telurito de potasio en E. coli CC118גpir recombinante determinada mediante crecimiento en LB suplementado con este marcador no antibiótico. (A) E. coli CC118גpir, control no transformado. (B) E. coli CC118גpir recombinante pF16. 


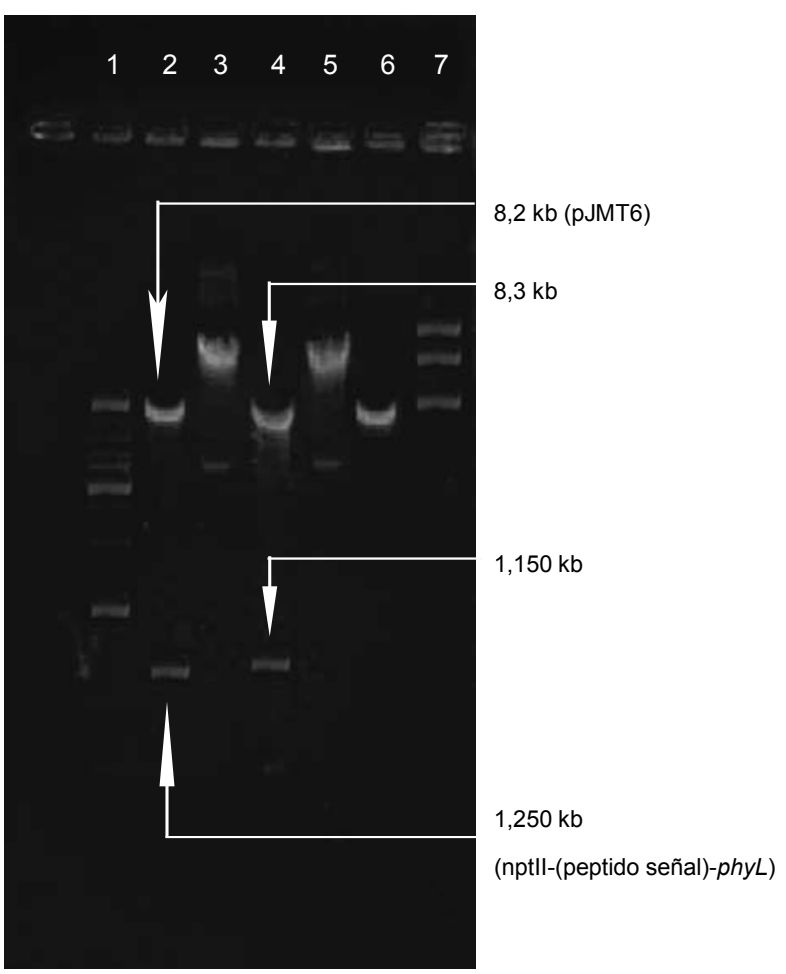

Figura 3. Patrón de restricción del plásmido recombinante pF16. (1) Marcador de peso molecular $1 \mathrm{~kb}$. (2) pF16 digerido con la enzima de restricción Notl. (3 - 5) pF16 sin digerir. (4) pF16 digerido con la enzima de restricción Clal. (6) pJMT6 digerido con la enzima de restricción Notl. (7) pJMT6 sin digerir.

Se purificó el ADN plasmídico y se realizó la digestión con las enzimas de restricción Not I y Cla I para liberar el inserto y analizar el tamańo de los plásmidos recombinantes. En la figura 3 se muestra el patrón de digestión de uno de estos plásmidos recombinantes: el designado $\mathrm{pF} 16$, purificado a partir del clon E. coli CC118 $\lambda$ pirF16, que mostró el tamaño esperado para la construcción resultante de la unión del vector pJMT6 y del fragmento Npt-APL. En la digestión con NotI el plásmido pF16 produjo un fragmento de aproximadamente 8,2 kb (pJMT6) y otro de 1,2 kb (Npt-APL). Con la enzima de restricción Cla I se obtuvieron dos fragmentos de aproximadamente $8,3 \mathrm{~kb}$ y $1,1 \mathrm{~kb}$. Ambas digestiones indican un tamaño de 9,4 kb para el plásmido recombinante, que se ajusta al tamańo esperado y confirma la presencia de la construcción recombinante inicialmente concebida en el transformante seleccionado.

Cuantificación de la actividad fitasa asociada a los extractos celulares del transformante $E$. coli CC118 $\lambda$ pirF16

Durante un periodo de $24 \mathrm{~h}$ se analizó la actividad fitasa de

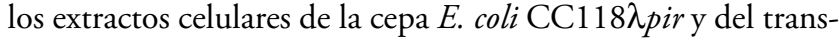
formante $E$. coli CC118 $\lambda$ pirF16 a partir de cultivos líquidos. Solo se pudo detectar la enzima activa al cabo de las $24 \mathrm{~h}$ de incubación de los cultivos. Como se muestra en la figura 4, la

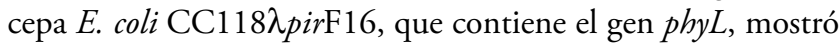
un valor de actividad fitasa significativamente mayor que la cepa receptora, indicando la expresión de este gen y la producción de la enzima activa.

Hasta el momento no se tiene ningún reporte de actividad

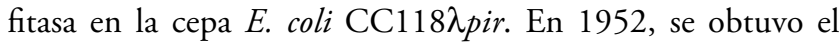
primer reporte de actividad fitasa en $E$. coli, pero sin ninguna caracterización de la enzima (Courtois y Manet 1952). Greiner et al. (1993) purificaron y caracterizaron dos fitasas de E. coli
K12 (ATCC 33965), las llamadas P1 y P2. Según lo reportado por estos autores, la actividad fitasa no fue detectable en el medio de cultivo. Mediante el procedimiento de shock osmótico y/o sonicación se alcanzo un $90 \%$ de actividad fitasa en los extractos celulares. Por lo tanto se determinó que las fitasas solamente podían ser localizadas de manera soluble en el espacio periplásmatico. Adicionalmente, la actividad fitasa se incrementaba marcadamente durante la fase estacionaria de crecimiento. En trabajos posteriores se demostró que la fitasa $\mathrm{P} 2$ presentaba un 95\% de homología con la fosfatasa hiperacídica pH 2,5 AppA de E. coli k12 (Greiner et al. 1997). Las fitasas son una clase especial de fosfatasas, por lo que ambas enzimas comparten características similares. Por lo tanto es posible que la pequeńa

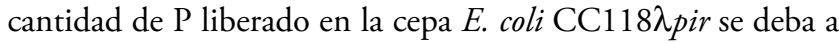
la naturaleza periplásmatica de todas las actividades fosfatasas debidamente reportadas para esta especie.

Los niveles de actividad fitasa obtenidos en los extractos celulares son bastante bajos, aun cuando se trabajó con extractos celulares obtenidos mediante sonicación. Mas del 90\% de las proteínas expresadas por la vía recombinante son encontradas en la fracción citoplasmática insoluble, resultado de la formación de cuerpos de inclusión (Kerovuo et al., 1998), por lo tanto esto podría ser una posible causa de esta baja actividad.

En los sobrenadantes de E. coli CC118 $\lambda$ pir y del transformante $E$. coli CC118 $\lambda$ pirF16 no se detectó actividad fitasa para ninguna de las dos cepas. En E. coli CC118 $\lambda$ pirF16, el resultado negativo puedo deberse a que el péptido señal de Azospirillum irakense utilizado en la construcción recombinante no sea reconocido en esta cepa de $E$. coli por ser dos especies de bacterias filogenéticamente diferentes. Según lo reportado en los trabajos sobre la expresión heteróloga de los genes de fitasa de Bacillus en $E$. coli, la actividad de estas enzimas es muy baja cuando los genes están bajo su propio péptido señal, la actividad fitasa más alta ha sido obtenida en los sistemas de expresión inducibles pET22b(+) (Kim et al. 1998, Farouk y Greiner 2004) y pQE-70 (Kerovuo et al. 1998).

Efecto de la expresión del gen $p h y L$ en el crecimiento de E. coli CC118 $\lambda$ pir

Se compararon las velocidades específicas de crecimiento de la cepa de $E$. coli CC118 $\lambda$ pir transformada con el plásmido recombinante $\mathrm{pF} 16$ y de $E$. coli CC118 $\lambda$ pir transformada con

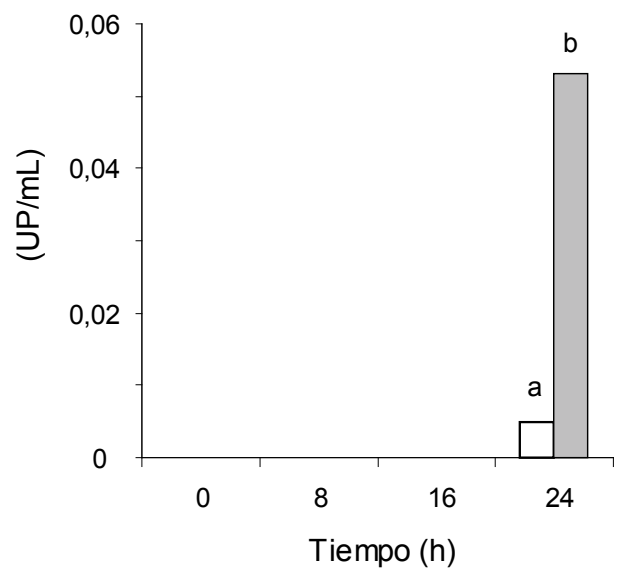

Figura 4. Actividad fitasa asociada a los extractos celulares de las

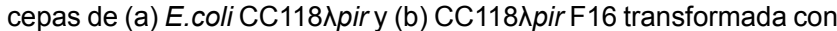
el gen phyL de Bacillus licheniformis (medida a través de la liberación de $\mathrm{P}$ inorgánico por degradación del ácido fítico $(\mathrm{UP} / \mathrm{mL})$. 


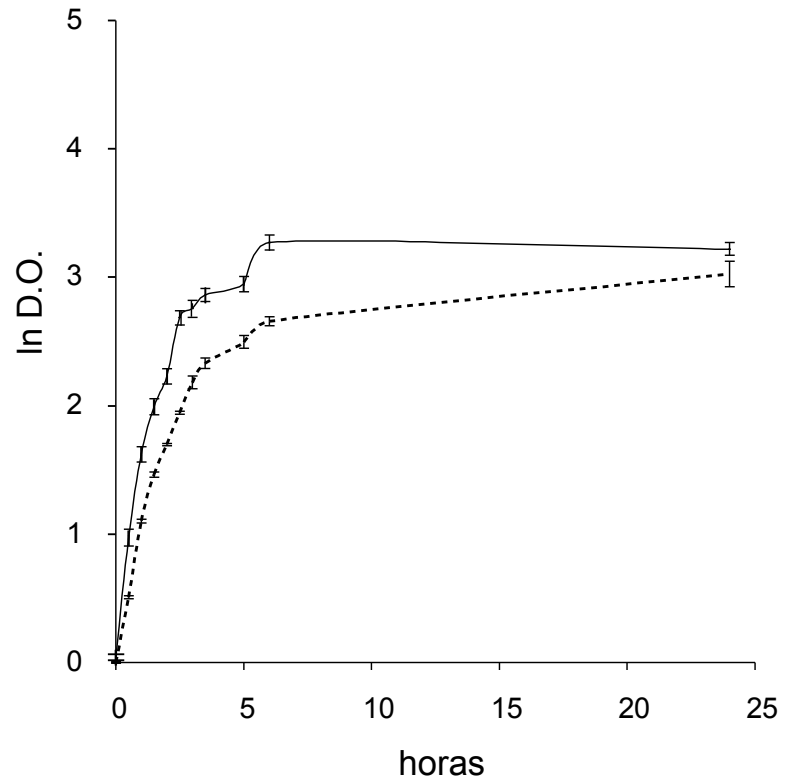

Figura 5. Crecimiento de las cepas de E.coli CC118גpir transformada con el plásmido recombinante pF16 (línea continua) y CC118גpir transformada con el vector pJMT6 sin el gen phyL (línea punteada) en medio LB líquido suplementado con ampicilina. Barras verticales: error estandar.

el vector pJMT6 sin el gen $p h y L$ (control) en cultivos líquidos en medio LB con ampicilina durante $24 \mathrm{~h}$ (Fig. 5). La fitasa de $B$. licheniformis, codificada por el gen $p h y L$, parece presentar cierta toxicidad para $E$. coli CC1 $18 \lambda$ pir, pues durante el período de tiempo analizado la velocidad específica de crecimiento de la cepa control $(0,8066)$ fue mayor que la correspondiente a la transformada con el gen phyL (0,5278). Kerovuo et al. (1998) sugirieron una supuesta toxicidad de las enzimas fitasas de Bacillus cuando eran transformadas en $E$. coli; esta toxicidad era detectada a través de la inhibición de crecimiento por la $E$. coli recombinante. Como posible explicación de la toxicidad de las fitasas recombinantes estos autores confirmaron la presencia de actividad ATPasa y ADPasa en estas enzimas. No es sorprendente entonces que la síntesis de la fitasa codificada por el gen $p h y L$ introducido en la célula hospedera, podría debilitar el crecimiento celular teniendo en cuenta que en el proceso de biosíntesis de proteínas es consumida una gran cantidad de energía representada en su mayoría por moléculas de GTP y ATP. Por otro lado la introducción de ADN foráneo en la célula hospedera causa una variedad de cambios en su fisiología y esta reportado que el más común esta asociado a la disminución del grado de crecimiento celular (Glick 1995).

Los resultados obtenidos apoyan que el empleo de sistemas de transformación basados en los vectores de integración cromosomal del tipo mini- $\operatorname{Tn} 5$ con marcadores de resistencia no antibióticos, como la resistencia a telurito de potasio, pueden ser una herramienta sumamente valiosa para la introducción y expresión de genes foráneos en $E$. coli, con vistas a su posterior transferencia a cepas de rizobacterias para su aplicación agrícola. Este sistema soluciona el problema del uso de marcadores genéticos inapropiados y de la transferencia de la información genética modificada a las poblaciones naturales. En este trabajo fue obtenido un plásmido recombinante que porta y expresa el gen $p h y L$ para la enzima fitasa de Bacillus licheniformis, en E. coli

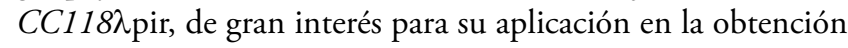

de bacterias que utilicen el fósforo orgánico del suelo con vistas a su empleo como biofertilizantes.

\section{Agradecimientos}

El presente trabajo se realizo como parte del proyecto CITMA: "Manipulación genética de bacterias promotoras del crecimiento de las plantas para su uso como fertilizantes biológicos", Número: 00300234.

\section{Literatura citada}

Courtois J. E. \& L. Manet. 1952. Recherches sur la phytase XVII. Les phytases du colibacille. Bull. Soc. Chim. Biol. 34(34): $265-278$

Dandie C.D., S. M. Thomas \& N. C. McClure. 2001. Comparison of a range of green fluorescent protein-tagging vectors for monitoring microbial inoculants in soil. Letters in Applied Microbiology 32: 26-30

de Lorenzo V., M. Herrero, J. M. Sánchez, et al. 1998. Mini-transposons in microbial ecology and environmental biotechnology. FEMS Microbiology Ecology 27: 211-224.

de Lorenzo, V. \& Timmis, K. (1994). Analysis and construction of stable phenotypes in gram-negative bacteria with $\operatorname{Tn} 5$ and Tn10-derived mini-transposons. Methods Enzymol. 235: 386-405.

Farouk A. \& R. Greiner. 2004. Recombinant bacterial phytases to reduce environmental phosphate pollution. Water and Environment Management. 7:165-172.

Glick B. R. 1995. Metabolic load and heterologous gene expression. Biotechnology Advances. 13:2 247-261.

Greiner R., E. Haller, U. Konietzny, et al. 1997. Purification and characterization of a phytase from Klebsiella terrigena. Arch.Biochem Biophys. 341: 201-206.

Greiner R., U. Konietzny \& K. D. Jany. 1993. Purification and characterization of two phytases from Escherichia coli. Arch Biochem. Biophys. 303: 107-113.

Hanahan D. 1983. Studies on transformation of Escherichia coli with plasmids. J. Mol. Biol. 166: 557-580.

Hansen, L. H., S. L. Sorensen \& Jensen, L. B. (1997). Chromosomal insertion of the entire Escherichia coli lactose operon into two strains of Pseudomonas using a modified mini Tn5 delivery system. Gene 186: 167-173.

Jorquera, M., O. Martínez, F. Maruyama, et al. 2008. Current and future biotechnological applications of bacterial phytases and phytase-producing bacteria. Microbes Environ. 23(3):182-191.

Kerovuo J., M. Lauraeus, P. Nurminen, et al. 1998. Isolation, Characterization, Molecular Gene Cloning, and Sequencing of a novel phytase from Bacillus subtilis. Applied and Environmental Microbiology. 64(6): 2079-2085.

Kim Y.O., J.K. Lee, H.K. Kim, et al. 1998. Cloning of the thermostable phytase gene (phyL) from Bacillus sp. DS11 and its overexpression in Escherichia coli. FEES Microbiology Letters. 162:185-191.

Konietzny U. \& R. Greiner. 2003. Phytic acid: Properties and determination. In: B. Caballero, L. Trugo \& P. Finglas (Eds.). Encyclopedia of Food Sciences and Nutrition. Academic Press, 2nd Edition, EN p. 4546-4555.

Li X., Z. Wu, W. Li, et al. 2007. Growth promoting effect of a transgenic Bacillus mucilaginosus on tabacco planting. Appl. Microbiol. Biotechnol 74: 1120-1125.

Richardson A. E. 2001. Prospects for using soil microorganisms to improve the acquisition of phosphorus by plants. Aust. J. Plant Physiol. 28: 897-906.

Rodríguez H.. \& R. Fraga. 1999. Phosphate solubilizing bacteria and their role in plant growth promotion. Biotechnology Advances. 17: 319-339 
Rodríguez H., R. Fraga, T. González, et al. 2006. Genetic of phosphate solubilization and its potencial applications for improving plant growth-promoting bacteria. Plant and Soil. 287(1-2): 15-21.

Sambrook J. \& D. W. Russell. 2001. Molecular cloning: a laboratory manual. (3ed.). Cold Spring Harbor Laboratory Press, N.Y.

Sánchez-Romero J. M., R. Díaz-Orejas \& V. de Lorenzo. 1998. Resistance to tellurite as a selection marker for genetic manipulations of Pseudomonas strains. Appl. Environ. Microbiol. 64: 4040-4046.

Shimizu Z. 1992. Purification and characterization of phytase from Bacillus subtilis (natto) N-77. Biosci. Biotechnol. Biochem. 56:1266-1269.
Steen I. 1998. Phosphorus availability in the 21st century: management of a non-renewable resource. Phosphorus and Potassium. 217: 25-31

Tye A. J., F. K. Siu, T. Y. Leung, et al. 2002. Molecular cloning and the biochemical characterization of two novel phytases from Bacillus subtilis 168 and Bacillus licheniformis. Appl Microbiol Biotechnol. 59:190-197.

Vohra A. \& T. Satyanarayana. 2003. Phytases: Microbial sources, production, purification and potencial biotechnological applications. Crit. Rev. Biotechnol. 23:29-60

Zahir, A. Z., M. Arshad \& W. T. Frankenberger, 2004. Plant Growth Promoting Rhizobacteria: Applications and Perspectives in Agriculture. Advances in Agronomy.81:97-167. 